\title{
YIELD PERFORMANCES OF PELLETED TRUE POTATO (TPS) SEEDS IN OUTDOOR SEEDBED GROWING
}

\author{
Gulsum OZTURK ${ }^{1 *}$, Zeynep DUMANOGLU ${ }^{2}$ \\ ${ }^{I}$ Ege University, Faculty of Agriculture, Department of Field Crops, Izmir, TURKEY \\ ${ }^{2}$ Bingol Univ., Faculty of Agriculture, Depart. of Biosystem Engineering, Bingol, TURKEY \\ *Corresponding author: gulsum.ozturk@ege.edu.tr
}

Received: 26.05 .2021

\begin{abstract}
Yield performances of pelleted true potato seeds were tested in the outdoor seedbed growing at BornovaIzmir, Turkey in 2017 and 2018. Micro yield trial was arranged in a Completely Randomized Design (CRD) with following treatments: seedling from pelleted seed (SPS), seedling from non-pelleted seed (SNPS), pelleted single seed (PSS), pelleted two (double) seed (PDS), pelleted three (triple) seed (PTS), non-pelleted seed (NS) and minituber (MT). The following results were obtained the PTS had the highest tuber number (9.1); the PDS had the highest single tuber weight similar to the control MT; the PTS had the highest plant yield (182.3 g); the PTS had the highest plot yield (1.0 kg) with the MT (Control); the PDS had the highest tuber width (3.4 cm) similar to the MT (control) and the PDS had the highest tuber length $(4.2 \mathrm{~cm})$ similar to the MT $(4.1 \mathrm{~cm})$ and PSS $(4.0 \mathrm{~cm})$

The high mean for the agronomical traits indicated that pelleted potato seeds could be successfully used in the outdoor seedbed growing.
\end{abstract}

Keywords: Generative seed, potatoes, potato yield traits, TPS technology

\section{INTRODUCTION}

Potato production using true potato seed (TPS) has been proposed as an alternative to the traditional potato production by tubers. This new technique involved TPS (generative seed) obtained from potato plants produced fruits under field conditions (Almekinders et al., 1996; Chujoy and Cabello, 2007). Almekinders et al. (2009) has reported that the International Potato Center (CIP) in Peru has worked on potato production by using TPS and small farmers have used this technique in producing potatoes.

Seedlings obtained from growing true seeds have been used in this proposed technique for a long time similar to tobacco growing. So seedlings from true seeds were easily transferred to seedbeds or to field conditions (Yildirim et al., 1985; Muthoni et al., 2014).

Using potato seeds directly under field conditions has disadvantage of germination and emergence due to its very small size (Dumanoglu, 2016). Using seedlings had also some growing difficulties due to adaptation problems. Therefore coating potato seed or pelleting has been proposed a new technique to cope with those problems (Cavuslar and Eser, 2002; Kavak and Eser, 2005; Chujoy and Cabello, 2007). Pelleting potato seed aims to have a uniform and heavy seed grain by coating them with several fertilizers, hormones and other nutrients (Kavak, 2006; Dumanoglu, 2016). This technology aims to reduce the cost and increase production in seed production (Gupta et al., 2004; Sinna et al., 2018). In addition, disease-free seed production and storage suitability is another advantage (Chujoy and Cabello, 2007; Sadavatti et al., 2018).

Variety Nif (101) one selection from the Andigena $x$ Tuberosum cross was released in 1998 (Ozturk and Yildirim, 2020). This genotype produces abundant fruits under field conditions so numerous true potato seeds (TPS) could be obtained. Therefore, it could be considered as suitable to TPS technology.

The objective of this study was to compare yielding performances of potato plants developed from various treatments of pelleted seed of this genotype.

\section{MATERIALS AND METHODS}

The study was conducted in the outdoor seedbeds of Department of Field Crops of the Faculty of Agriculture of the Ege University in 2017 and 2018. Seeds of the potato genotypes Nif (101) with abundant fruit production were used. The fruit were collected in the field preceding year and seeds were extracted as given by Midikoglu (1988); Ozturk and Yildirim (2020). 


\section{Pelleting true potato seed}

In this study, organic materials left after vegetative production were utilized. Therefore, the organic materials accepted as waste were added in the reproduction chain (Dumanoglu, 2020). True seeds of Nif variety were pelleted by using organic corn cob dust, leaves of artichoke, bean and pea leaves dust; inorganic clay (below $0.080 \mathrm{~mm}$ in sieve) and sugar-water mixture as adhesive. Approximately 10-12 g of the pelleting material was used in a batch seed pelleting. After this application, the seeds were kept in a dark room for 24 hours at $24{ }^{\circ} \mathrm{C}$ to dry in a moisture-free environment. True seeds of Nif variety with
0.4-0.8 gr thousand kernel weights were used in pelleting applications. The sizes of seed were increased 2.5-3 fold by this procedure (Dumanoglu and Ozturk, 2021). The pelleted seeds were germinated under controlled conditions such as $20-25{ }^{\circ} \mathrm{C}$; $60-70 \%$ humidity described by ISTA (2007) and the germination capacity was found to be $81.33 \%$.

\section{Seedbed trial}

Pelleted seeds containing 1, 2 and 3 seeds and four control variant shown in Table 1 were used in the yield trial conducted in the outdoor seedbeds. Temperature and precipitation during the trial recorded are given in Table 2.

Table 1. Three pelleted seed treatment and other controls of Nif variety planted in the seedbed trial

\begin{tabular}{ll}
\hline Code number & Treatment \\
\hline SPS & Seedling from pelleted seed \\
SNPS & Seedling from non-pelleted seed \\
PSS & Pelleted single seed \\
PDS & Pelleted two (double) seed \\
PTS & Pelleted three (triple) seed \\
NS & Non-pelleted seed \\
MT $^{*}$ & Minituber (Control) \\
\hline${ }^{*}: 10-12$ g minitubers were used &
\end{tabular}

Table 2. Temperature and precipitation during the trial recorded at Izmir-Turkey*

\begin{tabular}{|c|c|c|c|c|}
\hline \multirow[t]{2}{*}{ Months/Years } & \multicolumn{2}{|c|}{$2017-2018$} & \multicolumn{2}{|c|}{$2017-2018$} \\
\hline & \multicolumn{2}{|c|}{ Average Temperature $\left({ }^{0} \mathrm{C}\right)$} & \multicolumn{2}{|c|}{ Total Precipitation (mm) } \\
\hline March & 13.3 & 15,8 & 72.2 & 67.2 \\
\hline April & 16.6 & 19,3 & 15.7 & 11.3 \\
\hline May & 21.7 & 23,9 & 27.0 & 67.6 \\
\hline June & 26.5 & 26,8 & 1.8 & 29.8 \\
\hline July & 29.8 & 29,7 & 1.4 & 0.3 \\
\hline
\end{tabular}

Trial was planted on March, in 2017 and March, 2 in 2018. The yield trial was arranged in the Completely Randomized Design (CRD) with 3 replications. One plot consists of one row in 1.5 meter length was used. The spacing between rows was $50 \mathrm{~cm}$ and $20 \mathrm{~cm}$ on the rows. The planting depth was $1.5 \mathrm{~cm}$. The germination and emergency percentages of the trial was shown in Table 3.

Table 3. Percentages of seed emergence in the trial

\begin{tabular}{lccccc}
\hline & \multicolumn{5}{c}{ Emergence \% } \\
\cline { 2 - 6 } & $\begin{array}{c}\text { Pelleted single } \\
\text { seed }\end{array}$ & $\begin{array}{c}\text { Pelleted two } \\
\text { (double) seed }\end{array}$ & $\begin{array}{c}\text { Pelleted three } \\
\text { (triple) seed }\end{array}$ & $\begin{array}{c}\text { Non-pelleted } \\
\text { seed }\end{array}$ & $\begin{array}{c}\text { Minituber } \\
\text { (Control) }\end{array}$ \\
\hline 2017 & 80 & 80 & 80 & 73.3 & 80 \\
2018 & 80 & 80 & 80 & 73.3 & 80 \\
\hline
\end{tabular}

\section{Statistical Analyses}

The data obtained in the seedbed trial were analyzed by applying the standard analyses of variance technique given by the Acikgoz et al. (2004). The means of the traits were compared by using the standard Least Significance Difference test as described by Steel and Torrie (1980).

\section{RESULTS AND DISCUSSION}

The results of combined analysis over 2017 and 2018 at the measured characteristics are presented in Table 4 and the means of the treatments for measured traits are given in Table 5 and Table 6. 
The mean squares given in Table 4 indicated that all the seed treatments were significant at the $\mathrm{p} \leq 0.01$ level for the traits investigated. The treatment $x$ year interactions were non-significant for the yield characteristics. One unexpected result was the year source of variation significant for plot yield at the $p \leq 0.01$ level.

Table 4. Mean squares of the tuber characteristics obtained from the combined analysis of variance over 2017 and 2018.

\begin{tabular}{lcccccc}
\hline Source of variance & $\begin{array}{c}\text { Tuber } \\
\text { number }\end{array}$ & $\begin{array}{c}\text { Single tuber } \\
\text { weight }(\mathbf{g})\end{array}$ & Tuber yield $(\mathbf{g})$ & Plot yield $(\mathbf{k g})$ & $\begin{array}{c}\text { Tuber width } \\
(\mathbf{c m})\end{array}$ & $\begin{array}{c}\text { Tuber length } \\
(\mathbf{c m})\end{array}$ \\
\hline Treatment & $288.716^{* *}$ & $107.293^{* *}$ & $236.850^{* *}$ & $79.589^{* *}$ & $102.347^{* *}$ & $14.038^{* *}$ \\
Year & $0.822^{\mathrm{ns}}$ & $0.467^{\mathrm{ns}}$ & $3.901^{\mathrm{ns}}$ & $30.402^{* *}$ & $2.521^{\mathrm{ns}}$ & $1.371^{\mathrm{ns}}$ \\
Treatment $x$ Year & $1.118^{\mathrm{ns}}$ & $1.194^{\mathrm{ns}}$ & $2.171^{\mathrm{ns}}$ & $1.248^{\mathrm{ns}}$ & $0.917^{\mathrm{ns}}$ & $1.060^{\mathrm{ns}}$ \\
\hline${ }^{* *}:$ significant at the $\mathrm{p} \leq 0.01$ probability level & & & & & \\
ns: non-significant & & & & & &
\end{tabular}

Table 5. Means of the tuber number, single tuber weight $(\mathrm{g})$, plant yield $(\mathrm{g})$, tuber width $(\mathrm{cm})$ and tuber length $(\mathrm{cm})$ based on combined analysis over in 2017 and 2018

\begin{tabular}{lccccc}
\hline Treatment & $\begin{array}{c}\text { Tuber } \\
\text { number }\end{array}$ & $\begin{array}{c}\text { Single tuber } \\
\text { weight }(\mathbf{g})\end{array}$ & $\begin{array}{c}\text { Plant yield } \\
(\mathbf{g})\end{array}$ & $\begin{array}{c}\text { Tuber width } \\
\text { (cm) }\end{array}$ & $\begin{array}{c}\text { Tuber } \\
\text { length } \\
\text { (cm) }\end{array}$ \\
\hline Seedling from pelleted seed (SPS) & 8.1 & 15.1 & 124.2 & 2.7 & 3.8 \\
Seedling from non-pelleted seed (SNPS) & 5.7 & 15.2 & 84.8 & 2.6 & 3.8 \\
Pelleted single seed (PSS) & 6.3 & 24.0 & 150.1 & 3.2 & $\mathbf{4 . 0}$ \\
Pelleted double seed (PDS) & 5.7 & $\mathbf{2 7 . 0}$ & 152.3 & $\mathbf{3 . 4}$ & $\mathbf{4 . 2}$ \\
Pelleted triple seed (PTS) & $\mathbf{9 . 1}$ & 20.1 & $\mathbf{1 8 2 . 3}$ & 3.0 & 3.8 \\
Non-pelleted seed (NS) & 2.8 & 13.8 & 38.8 & 2.2 & 3.5 \\
Minituber (MT) & 4.5 & $\mathbf{2 6 . 3}$ & 118.6 & $\mathbf{3 . 4}$ & $\mathbf{4 . 1}$ \\
\hline LSD $_{(0.05)}$ & 0.362 & 1.576 & 8.979 & 0.126 & 0.187 \\
\hline
\end{tabular}

The means of seed treatments for the yield characteristics are shown in Table 5. The highest mean for tuber number was obtained from the pelleted 3 seeds (PTS) (9.1). The highest single tuber weights were obtained from the pelleted 2 seeds (PDS) $(27.0 \mathrm{~g})$ and the control (minituber) (26.3 g). The lowest mean for single tuber weight was for non-pelleted seed (NPS) (13.8 g). Yildirim et al. (1987) have grown seedlings of Andigena clone R.68 and R.143 in field and compared with normal size seed tuber. Tuber yield obtained from the transferred seedlings were lower than that of the seed tuber. Caliskan et al. (2006) reported the yield of the seedlings from main product regions were higher than early product regions. The decrease in yield for seedling as compared to tuber growing could be due to stress during seedling production and also for some earliness problems. In our study pelleted seed had higher tuber number and tuber weight as compared to seedling performance (5.7 vs 9.1) and (15.2 g vs $27.0 \mathrm{~g}$ ). In this study pelleted seeds have advantage of development instead of adaptation to new transferred soil conditions. Therefore, they developed early as compared to the seedling $\mathrm{s}$ in early growing.

When the seed treatments were compared for plant yield the highest plant yield was obtained from the pelleted 3 seeds combination (182.3 g) followed by the pelleted 2 seed $(152.3 \mathrm{~g})$ and pelleted 1 seed $(150.1 \mathrm{~g})$. The controls, non-pelleted seedlings, (84.8 g) and mini tuber $(118.6 \mathrm{~g})$ were behind them. The lowest mean for plant yield was obtained from non-pelleted seed (NS) (84.8 g). Midikoglu (1988) has reported the emergence of pelleted seed in field conditions as low as $20 \%$ and not recommended usage of pelleted seed in field production. Yildirim et al. (1985) has reported high plant yield from the 3 seedlings grown in $30 \mathrm{~cm}$ row spacing. In this study the pelleted 3 seed treatment (PTS) was found to have the highest plant yield confirming their findings. The pelleted single seed (PSS) and double seed (PDS) had also high plant yield in this study. The variance between two years were not significant for single tuber yield and plant yield indicating the similarity of maintenance conditions in two consecutive years. Seed tubers were used in the traditional potato production and the maintenance of seed tubers had contained difficulties during the growing seasons. But the pelleted seed could be stored easily in a cold storage thus giving chance to be used in consecutive seasons. The pelleted seed technology will have a chance of usage in the seed market. Unfortunately, at the moment the coated potato seeds are not sold like other vegetable and flower seeds in Turkey. This new technology will have a chance to be used in near future.

Tuber width had the highest value for mini tuber (MT) and Pelleted double seed (PDS) $(3.4 \mathrm{~cm})$, Pelleted single seed (PSS) $(3.2 \mathrm{~cm})$, Pelleted triple seed (PTS) $(3.0 \mathrm{~cm})$ follow them. The tuber length was higher for pelleted 2 seed (PDS) and minituber (MT) $(4.1 \mathrm{~cm})$. The lowest tuber length was obtained from the non-pelleted seed (NS) such as $(3.5 \mathrm{~cm})$. The high tuber size means close to control indicated the possibility of obtaining large tubers from pelleted seeds. 
The mean square for years was found to be significant at the $\mathrm{p} \leq 0.01$ level for plot yield therefore the means for
2017 and 2018 and mean over 2017 and 2018 are given and discussed separately.

Table 6. Means of the plot yield (kg) for 2017 and 2018 and means over two years for the pelleted seed and the control treatments.

\begin{tabular}{lccc}
\hline Treatment & $\mathbf{2 0 1 7}$ & $\mathbf{2 0 1 8}$ & Mean \\
\hline Seedling from pelleted seed (SPS) & 0.6 & 0.7 & 0.6 \\
Seedling from non-pelleted seed (SNPS) & 0.4 & 0.5 & 0.5 \\
Pelleted single seed (PSS) & 0.7 & 0.9 & 0.8 \\
Pelleted double seed (PDS) & 0.7 & 0.9 & 0.8 \\
Pelleted triple seed (PTS) & $\mathbf{0 . 9}$ & $\mathbf{1 . 0}$ & $\mathbf{1 . 0}$ \\
Non-pelleted seed (NS) & 0.3 & 0.4 & 0.3 \\
Minituber (MT) & 0.8 & $\mathbf{1 . 0}$ & 0.9 \\
\hline Mean & 0.6 & $\mathbf{0 . 8}$ & \\
\hline LSD (Year) $(0.05): 0.042$ & & \\
LSD (Treatment) & & & \\
\hline
\end{tabular}

It could be seen in Table 6 that significantly high plot yield was obtained in 2018 . The highest plot yield $(0.9 \mathrm{~kg})$ was obtained from the pelleted 2 seeds (PDS) in 2017 and from mini tuber (MT) $(1.0 \mathrm{~kg})$ and the pelleted three seed (PTS) $(1.0 \mathrm{~kg})$ in 2018. Yildirim et al. (1987) reported the tuber size was the limiting factor for yield in seedlings growing. In this study the plot yield for pelleted was found to be in the same group with control. In addition, the high averages of pelleted seed for second year indicated that also pelleted seeds may be maintainable safely in the at least for one year in storage.

The distributions of tuber characteristics measured in the seedbed growing for pelleted seed were shown in figures $1,2,3,4$ and 5 .

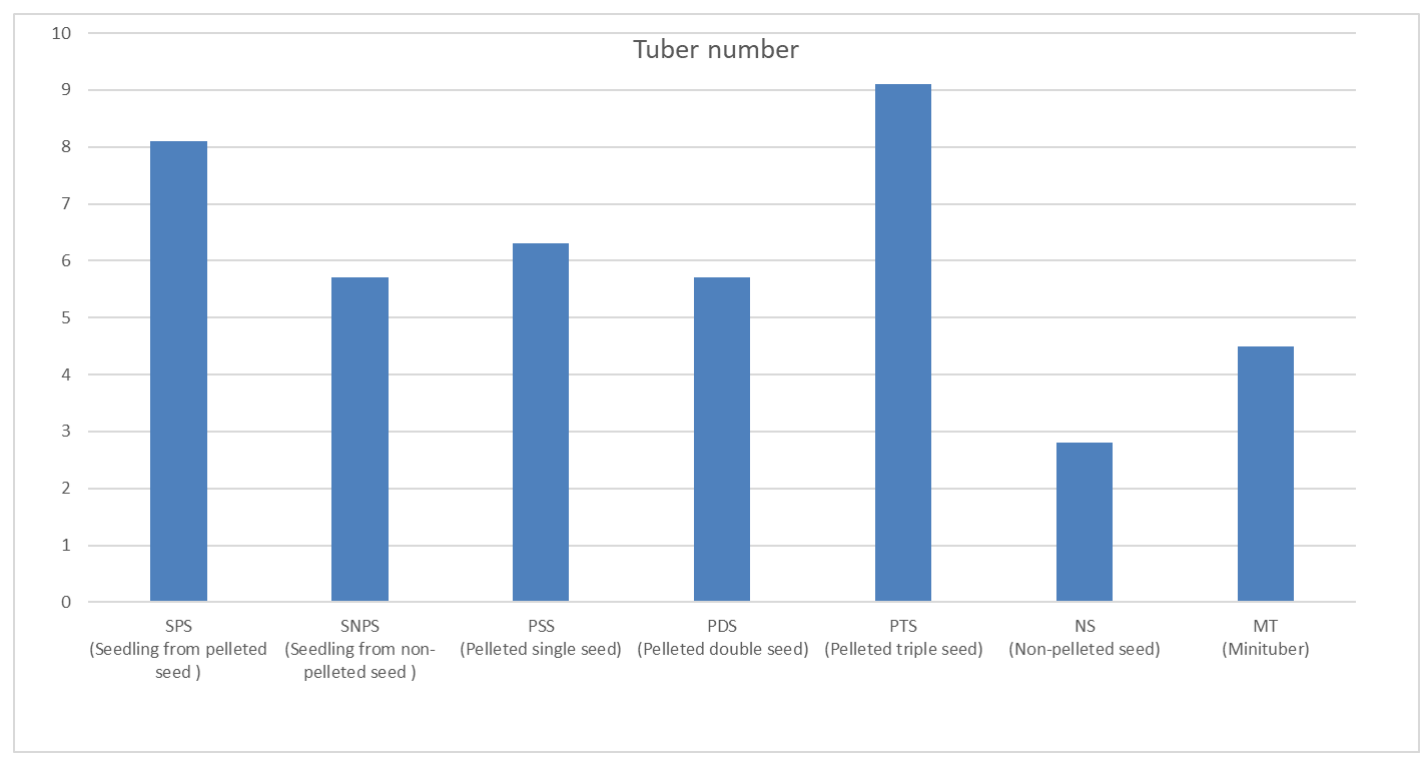

Figure 1. Histograms of tuber number of the pelleted seed grown in the seedbed 


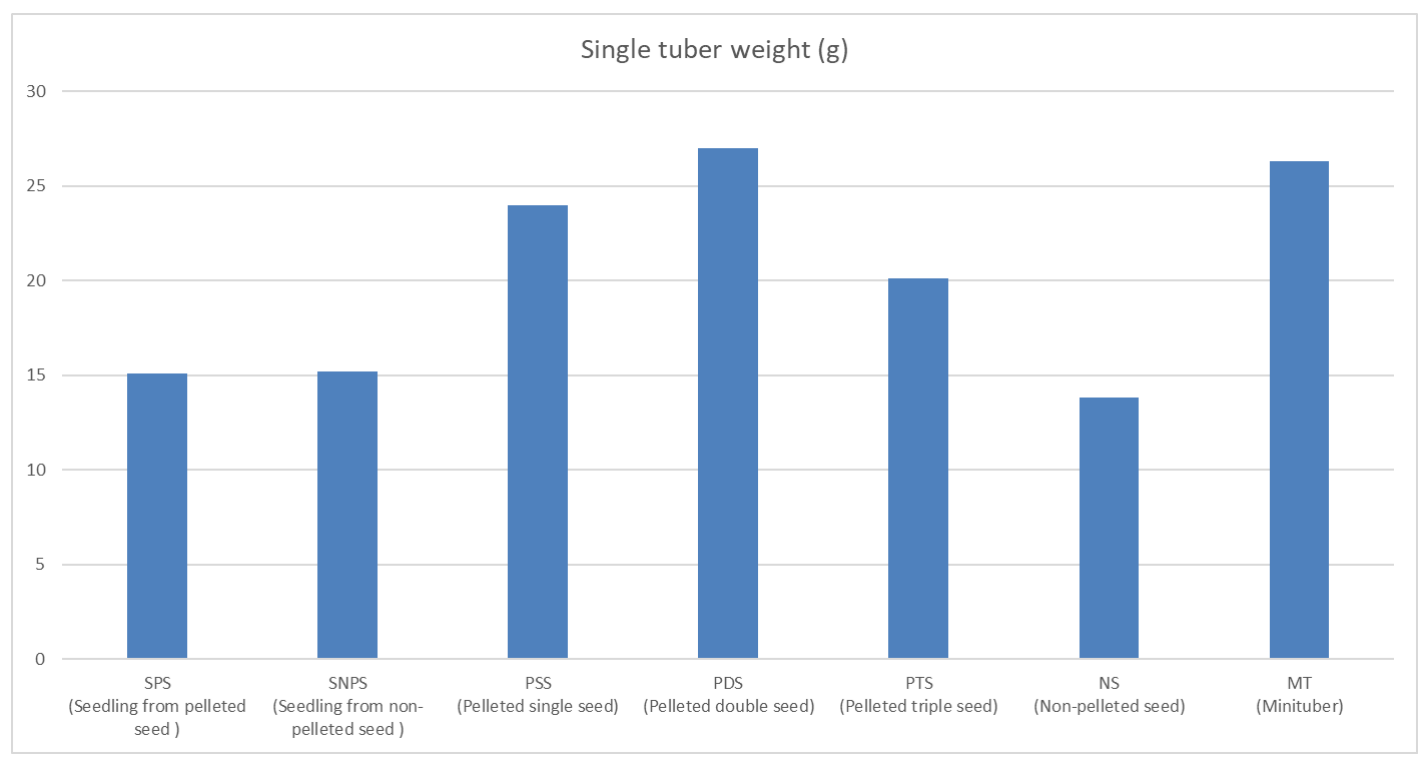

Figure 2. Histograms of the single tuber weight (g) of the pelleted seed grown in the seedbed

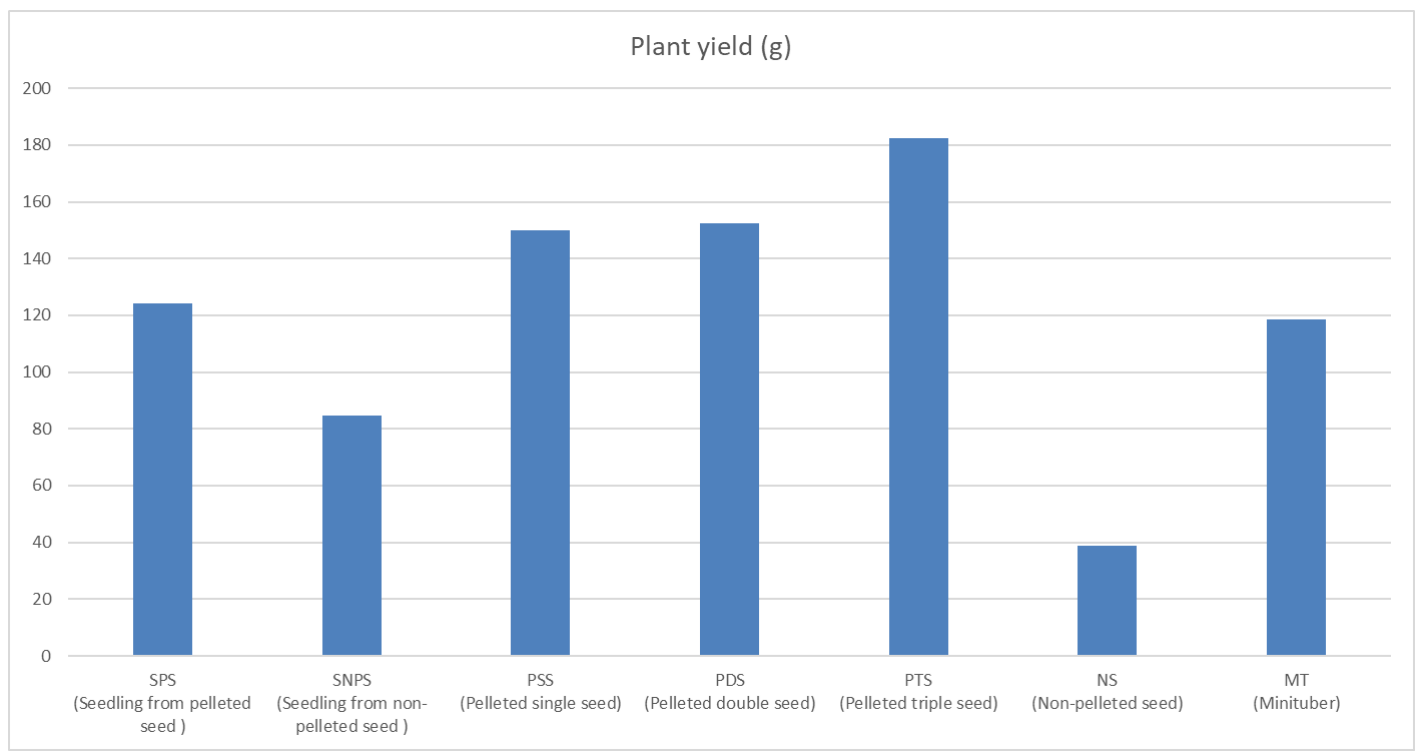

Figure 3. Histograms of plant yield (g) of the pelleted seed grown in the seedbed 


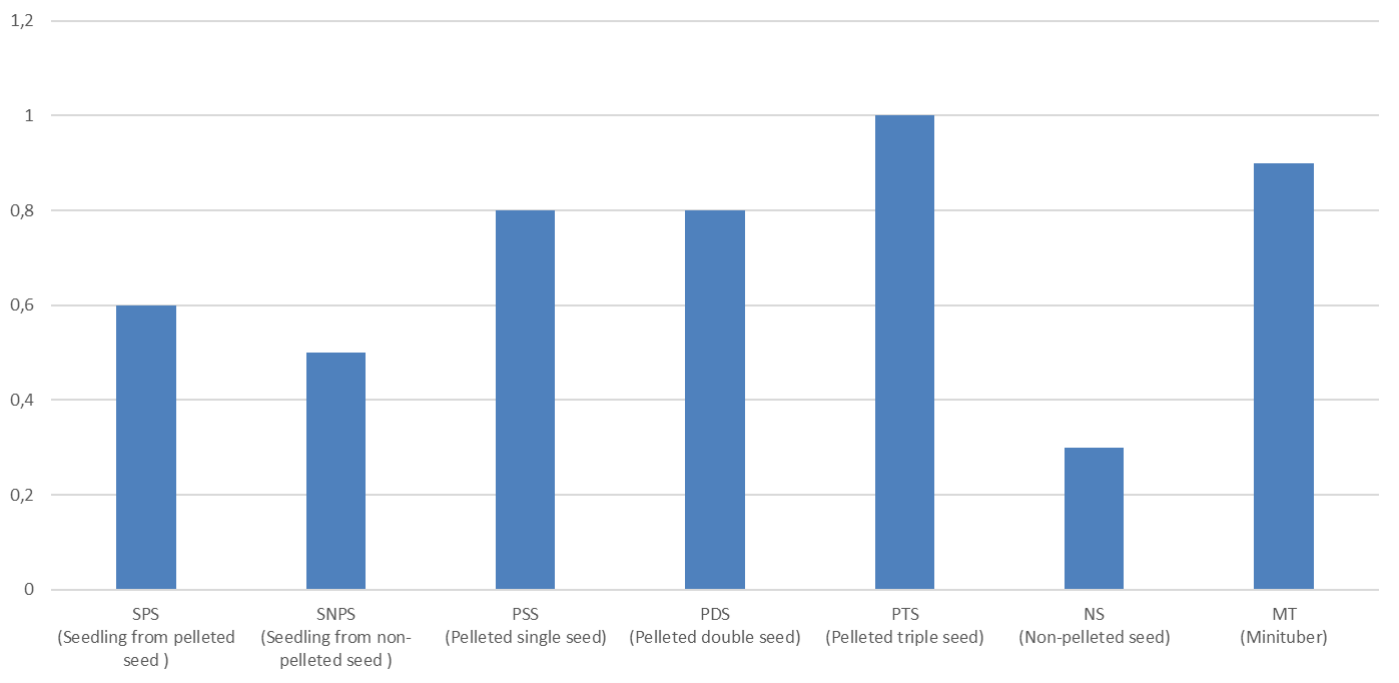

Figure 4. Histograms of plot yield $(\mathrm{kg})$ of the pelleted seed grown in the seedbed

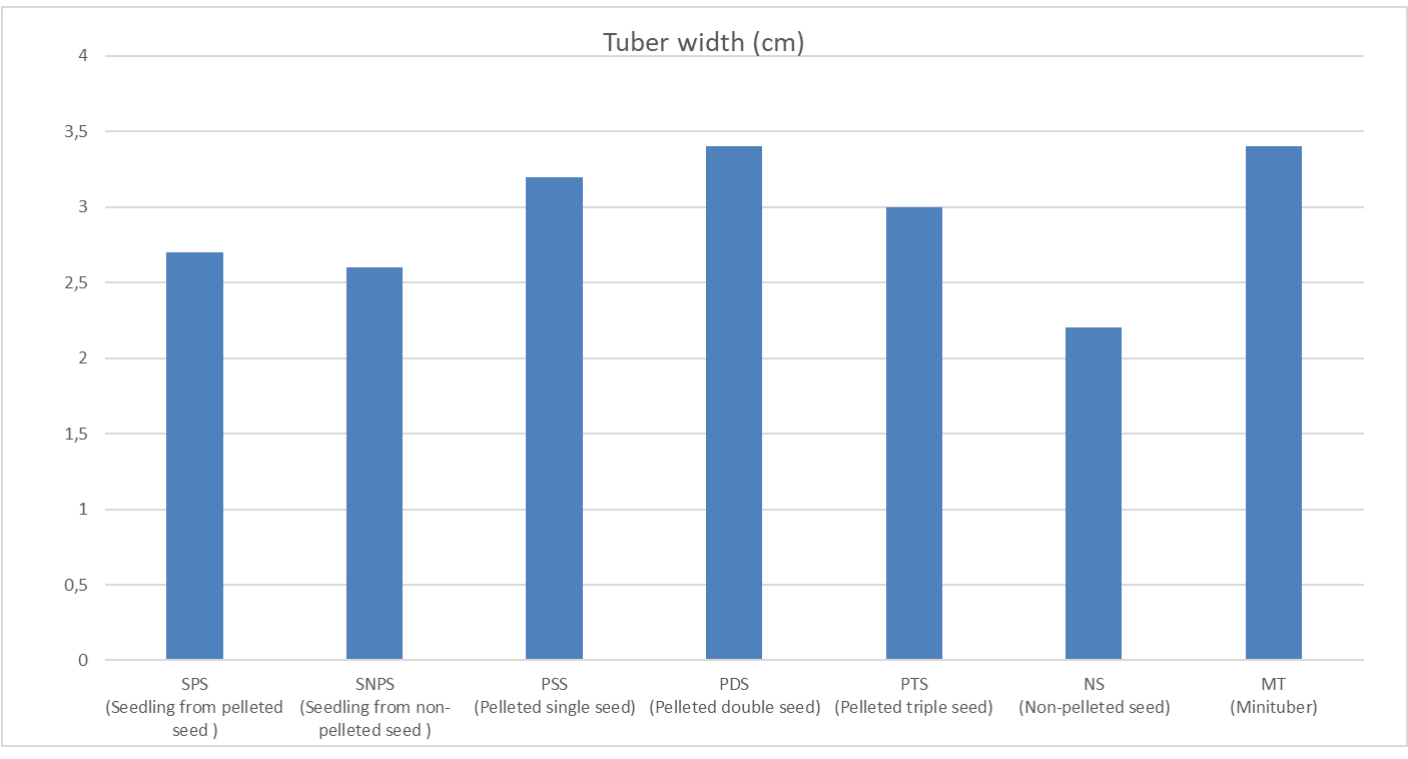

Figure 5. Histograms of tuber width $(\mathrm{cm})$ of the pelleted seed grown in the seedbed 


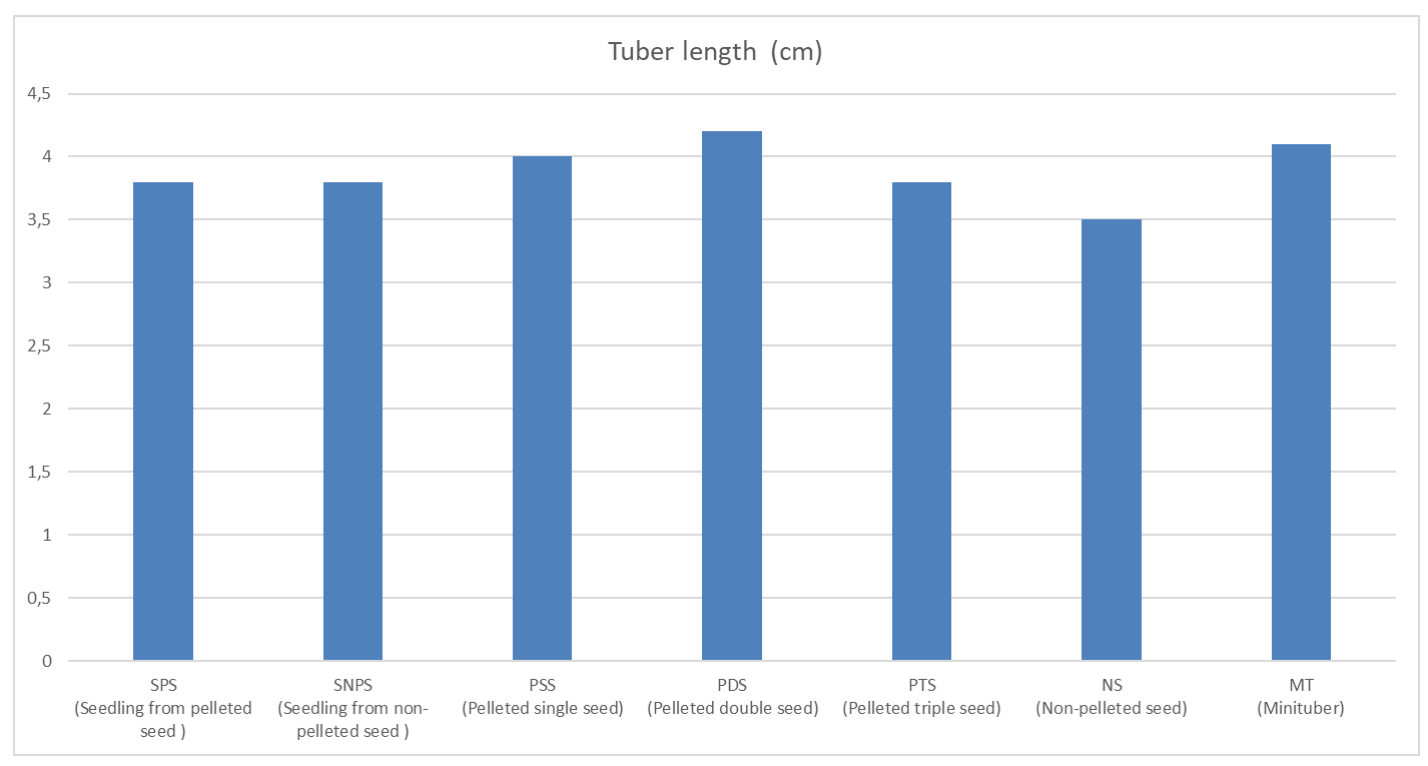

Figure 6. Histograms of tuber length $(\mathrm{cm})$ of the pelleted seed grown in the seedbed

\section{CONCLUSION}

Pelleted seeds had higher tuber number and single tuber weight, as compared to the seedlings and mini tubers; pelleted seeds had close means as compared to mini tuber growing for single tuber yield and plot yield. Therefore, the use of pelleted seeds in potato cultivation may be suitable to outdoor production in seedbeds. Increasing the pellet size could have a positive effect in field growing. In addition, organic materials treated as waste could be gained by utilizing this way.

The pelleted seeds were disease free and low production cost could be an alternative to the traditional potato production using tubers seeds. The application of pelleted seed technic requires suitable soil preparation which is difficult in comparatively large field areas. Therefore this technology could be safely used in small size plantation areas and gardens. In near future the market developed pelleted seeds will be an innovative approach in production from pelleted potato seeds similar to vegetables and flowers.

\section{LITERATURE CITED}

Acikgoz, N., E. Ilker, A. Gokcol. 2004. Evaluation of biological research in computer. E.U. TOTEM, Publication No:2, Izmir (in Turkish).

Almekinders, C.J.M., A.S. Chilver, H.M. Reina. 1996. Current status of the TPS technology in the world. Potato Research 39: $289-303$.

Almekinders, C.J.M., E. Chujoy, G. Thiele. 2009. The Use of True Potato Seed as Pro-poor Technology: The Efforts of an International Agricultural Research Institute to Innovating Potato Production. Potato Research 52: 275-293.

Caliskan, M.E., H. Arioglu, N. Kusman, S. Caliskan. 2006. Yield potential and using possibilities of true potato seed technology in Turkey. IV. National Potato Congress, 06-08 September, 38-45p (in Turkish).

Cavuslar, F. and B. Eser. 2002. A Research on the Application of Film Coating Technique in Tomato Seeds. Turkey I. Seed Congress, 11-13 September,Izmir, 191-200p (in Turkish).
Chujoy, E. and R. Cabello. 2007. True Potato Seed (TPS). Potato Research 50: 323-325.

Dumanoglu, Z. 2016. Determination of Appropriate Coating and Pelleting Methods for Some Medicinal and Aromatic Plant Seeds. Ege Un. Science Inst. Department of Agricultural Machinery and Technologies Engineering, PhD Thesis, Izmir.

Dumanoglu, Z. 2020. Evaluation of vegetable waste from renewable energy sources. Innovative Approaches in Agriculture, Sustainable Agriculture and Biodiversity. Ed: Kagan Kokten, ISBN: 978-625-7687-38-6, 461-473, Bingol (in Turkish).

Dumanoglu, Z. and G. Ozturk. 2021. A research on improving seed quality (pelleting) in true potato of 101 (Nif) genotype. Fresenius Environmental Bulletin 30: 10983-10988.

Gupta, V.K., K. Thakur, S.K. Dubey, S. Pandey and U. Sah. 2004. True Potato Seed-An Alternative Technology for Potato Production in North-eastern Hill Region. Technical Bulletin No. 64.

ISTA. 2007. International Rules for Seed Testing Book.

Kavak, S. and B. Eser.2005. Polymers used in the germination of some seeds and coated film without on the Elimination of Negative Impact on Research, Turkey II. Seed Congress 911 November,Adana, 76-81p (in Turkish).

Kavak S. 2006. Effects of Different Polymer Coating Materials and Applications on Storage Life and Aging of Onion Seeds, Ege Ün. Science Inst. Department of Horticulture, PhD Thesis, Izmir.

Midikoglu, N. 1988. Studies on potato seed pelleting. Ege Un. Science Inst. Department of Field Crops, Master's thesis Thesis, Izmir.

Muthoni, J. J. Kabira, H. Shimelis, R. Melis. 2014. Producing potato crop from true potato seed (TPS): A comparative study. AJCS. 8(8):1147-1151.

Ozturk, G. and Z. Yildirim. 2020. New Potato Breeding Clones for Regional Testing in Western Turkey. Turkish Journal of Field Crops 25: 131-137.

Sadavatti, M., R.K. Samadhiya, S. Kumar, S.P. Singh, S. Roy, S.K. Chattabakati. 2018. Performance of TPS Lines under Raised and Brick Bed Nursery Methods for Tuberlet Production in North Central India. Indian Journal of Hill Farming 31: 290-294.

Sinna, S., P. Paratnash, S. Kusvaha, P. Kumar, S. Kumar. 2018. Comparison of Potato Cultivation through TPS and HYV 
under Diverse Climatic Conditions of Bihar. Int.J. Curr. Microbiol. App. Sci. 7: 4918-4923.

Steel, R.G.D. and J.H. Torrie. 1980. Principles and Procedures of Statistics. McGaw-Hill Book Company, Inc. N.Y.

Yildirim, M.B., Z. Yildirim, O. Caylak. 1985. Potato production from true potato seed. Controlled and Certified Seed
Production and Distribution Problems in Turkey Symposium, 8-10 February,183p (in Turkish).

Yildirim, M.B., Z. Yildirim, O. Caylak. 1987. Potato production from true seed. DOGA. Turkish Journal of Agriculture and Forestry 11: 168-170. 